\title{
A novel technique of antegrade transapical arch and thoracic aortic endovascular repair with a triple-barrel graft
}

\author{
Robert Shahverdyan, MD, ${ }^{\mathrm{a}}$ Navid Madershahian, $\mathrm{MD},{ }^{\mathrm{b}}$ and Michael Gawenda, $\mathrm{MD},{ }^{\mathrm{a}}$ Cologne, Germany
}

The complete endovascular treatment of pathologies of the aortic arch and proximal descending thoracic aorta (TEVAR) reduces surgical trauma. The recently developed chimney technique was successfully performed in our center in limited cases as double-chimney (triple-barrel graft) technique in the aortic arch. With respect to the transapical implantation of an aortic stent-graft, various groups have described antegrade transapical TEVAR (TaTEVAR) of both the ascending and descending aorta. ${ }^{1-3}$ On the basis of these limited results, we undertook for the first time the application of triple-barrel technique by antegrade implantation of an aortic stent-graft through the transapical route of a beating heart to treat a contained rupture of the aortic arch caused by a penetrating aortic ulcer.

\section{CLINICAL SUMMARY}

A 76-year-old man with multiple comorbidities was seen for general weakness, long-lasting shortness of breath, and huskiness. Contrast-enhanced computed tomography revealed contained rupture of the aortic arch caused by a penetrating aortic ulcer with concomitant development of a pseudoaneurysm (72 mm; Figure 1). Cardiac surgeons rejected conventional and hybrid procedures. Transfemoral TEVAR was not possible because of the 7-mm lumen of the abdominal aorta. TaTEVAR combined with a transcarotid and transaxillary approach for deployment of the chimney-grafts was therefore chosen. Approval for this procedure was obtained from institutional review board.

The procedure was performed with the patient under general anesthesia in the hybrid operating room with ceilingmounted angiographic $\mathrm{C}$-arm system and transesophageal echocardiography throughout the whole procedure. After a 5-cm minithoracotomy incision in the left sixth intercostal space, the pleura was opened and a pericardiectomy was performed, exposing the left ventricular apex. A pericardial pacing wire was placed to induce rapid pacing. Then 2 pledgeted U-shaped purse-string sutures were placed in

From the Departments of Vascular and Endovascular Surgery ${ }^{\mathrm{a}}$ and Cardiothoracic Surgery, ${ }^{\mathrm{b}}$ University Hospital of Cologne, Cologne, Germany.

Disclosures: Authors have nothing to disclose with regard to commercial support.

Received for publication Aug 2, 2012; revisions received Oct 16, 2012; accepted for publication Feb 12, 2013; available ahead of print March 8, 2013.

Address for reprints: Robert Shahverdyan, MD, Kerpener Strasse 62, D-50937,

Cologne, Germany (E-mail: robert.shahverdyan@uk-koeln.de).

J Thorac Cardiovasc Surg 2013;145:1670-1

$0022-5223 / \$ 36.00$

Copyright (c) 2013 by The American Association for Thoracic Surgery

http://dx.doi.org/10.1016/j.jtcvs.2013.02.024

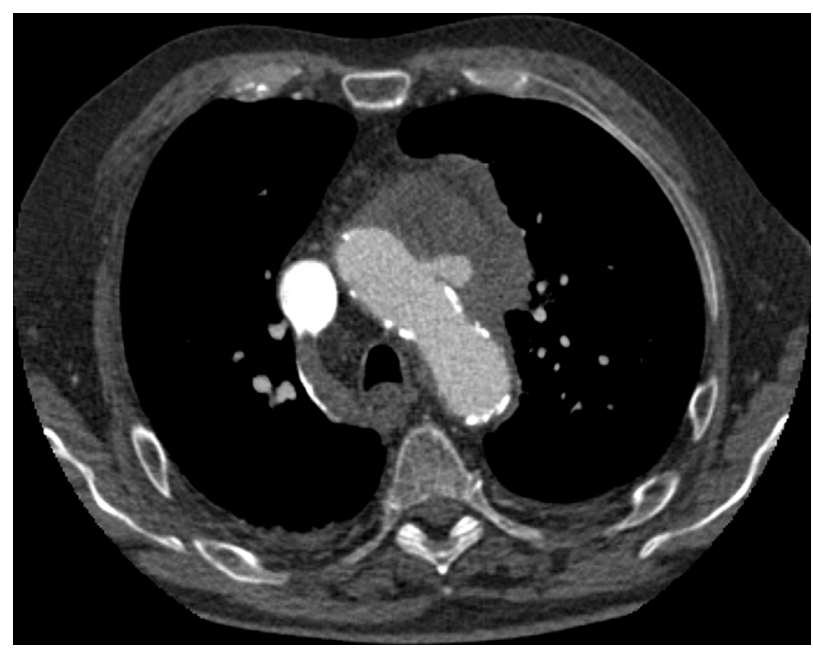

FIGURE 1. A 2-dimensional computed tomographic angiogram of the thoracic aorta.

the left ventricular apex. After administration of 10,000 units of heparin, the left ventricle was cannulated through an 18-gauge needle. A standard guide wire was advanced across the aortic valve. After the $6 \mathrm{~F}$ multipurpose catheter was advanced over a $6 \mathrm{~F}$ sheath, the standard wire was exchanged for an extra Lunderquist double-curved stiff wire (Cook Inc, Bloomington, Ind). By changing the 6F sheath to a longer 24F sheath, passage of the delivery system of the aortic stent-graft (TGE373720 CTAG; W. L. Gore \& Associates, Inc, Flagstaff, Ariz) to the proximal descending aorta was possible. Through short cut-down incisions, the left common carotid and right subclavian arteries were exposed and punctured. Then GORE Viabahn $(10 \times 100 \mathrm{~mm})$ and Excluder (PXC181000) legs were inserted to the ascending aorta guided by Amplatz super-stiff guide wires through $12 \mathrm{~F}$ and 18F GORE DrySeal sheaths. Simultaneously, the CTAG was introduced. The chimneys were introduced slightly deeper than the CTAG, with an overlapping length of $5 \mathrm{~cm}$. Next, the main stent-graft-and, shortly after, both chimney-grafts-were deployed under rapid left ventricular pacing with heart rate of 180 to 200 beats/min with reduction of systolic blood pressure under $60 \mathrm{~mm} \mathrm{Hg}$ to prevent the migration of the grafts (Figure 2). The left subclavian artery was not preserved due to only coverage of a short segment of the thoracic aorta. The completion angiogram showed no endoleaks and patent supra-aortic arteries. After withdrawal of all devices, the apex was closed with purse-string sutures. All incisions were closed in anatomic layers. 


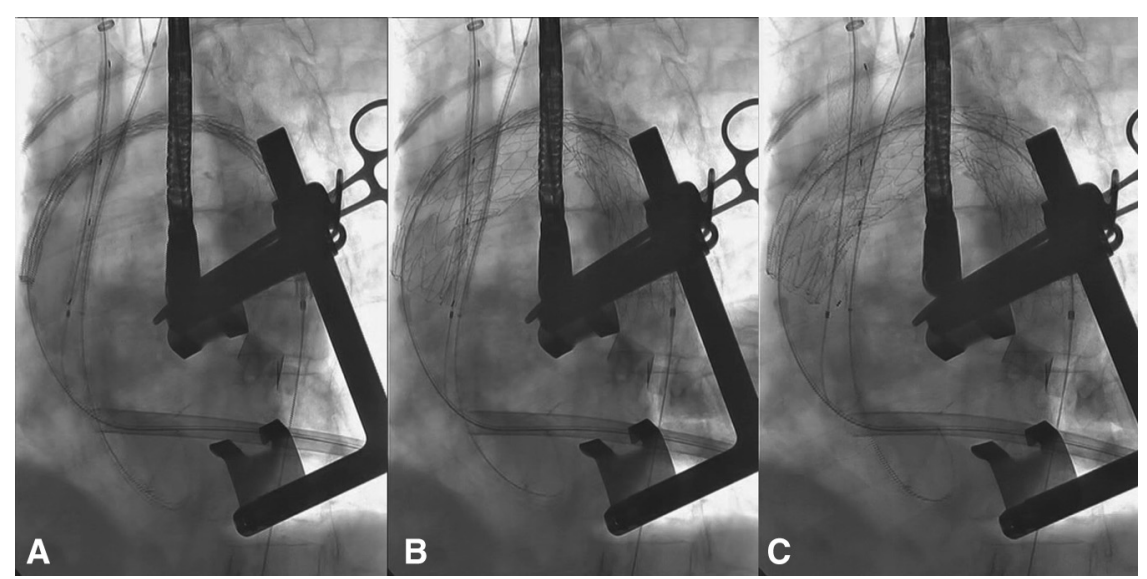

FIGURE 2. Intraoperative angiogram showing deployment of all 3 stent-grafts. A, Correct positioning of all 3 stent-grafts. B, Deployment of the aortic stent-graft. C, Simultaneous deployment of both chimney-grafts.

The operative time was 145 minutes. The patient showed no signs of neurologic deficits or bleeding. Echocardiography demonstrated normal left ventricular function. Computed tomographic scan revealed low-flow "gutter" endoleak with patent chimney-grafts and supra-aortic arteries except for the left subclavian artery.

\section{DISCUSSION}

The triple-barrel technique was applied for the first time through transapical access, making feasible the deployment of TEVAR of an aortic arch with minimal surgical trauma for the patient with multiple comorbidities and high perioperative risk.

MacDonald and colleagues ${ }^{1}$ first described a case of TaTEVAR in a single patient. Although that patient died, the procedure was technically successful and required 8.5 hours. Long operative time is a considerable drawback in such patients with heavily reduced general health condition. Our procedure required only 145 minutes. We did not find any site bleeding during transapical access. In addition, neither valvular nor ventricular dysfunction was seen.

The main concern with the chimney technique is the appearance of gutter endoleak. The deployment of slightly oversized aortic stent-grafts may reduce the risk for gutter endoleak and for compression of the chimney-graft. To provide good sealing, we oversized the aortic stent-graft by
$20 \%$. There are no data available in the literature on how much oversizing is needed. Another factor in the development of a gutter endoleak is the length of the chimneygrafts and consequently the overlapping of all grafts. Various authors have recommended overlaps greater than 2 to $3 \mathrm{~cm}^{4}$ or at least $7 \mathrm{~cm}^{5}$; however, the safe and precise overlap length needed requires further study.

In conclusion, although both TaTEVAR and chimney technique are controversial and not completely proven, the transapical double-chimney technique can be performed with off-the-shelf devices in limited cases with no other treatment options.

\section{References}

1. MacDonald S, Cheung A, Sidhu R, Rheaume P, Grenon SM, Clement J. Endovascular aortic aneurysm repair via the left ventricular apex of a beating heart. $J$ Vasc Surg. 2009;49:759-62.

2. Szeto WY, Moser WG, Desai ND, Milewski RK, Cheung AT, Pochettino A, et al Transapical deployment of endovascular thoracic aortic stent graft for an ascending aortic pseudoaneurysm. Ann Thorac Surg. 2010;89:616-8.

3. Uthoff H, Garcia-Covarrubias L, Samuels S, Benenati JF, Moreno NL, Katzen BT. Transapical endovascular aortic repair to treat complex aortic pathologies. Ann Thorac Surg. 2012;93:1735-7.

4. Lachat M, Frauenfelder T, Mayer D, Pfiffner R, Veith FJ, Rancic Z, et al. Complete endovascular renal and visceral artery revascularization and exclusion of a ruptured type IV thoracoabdominal aortic aneurysm. J Endovasc Ther. 2010; 17:216-20.

5. Kolvenbach RR, Yoshida R, Pinter L, Zhu Y, Lin F. Urgent endovascular treatment of thoraco-abdominal aneurysms using a sandwich technique and chimney graftsa technical description. Eur J Vasc Endovasc Surg. 2011;41:54-60. 